\title{
К ВОПРОСУ О СОВЕРШЕНСТВОВАНИИ МЕЖДУНАРОДНЫХ СТАНДАРТОВ В ОБЛАСТИ БЕЗОПАСНОСТИ ТРУДА И ОХРАНЫ ЗДОРОВЬЯ
}

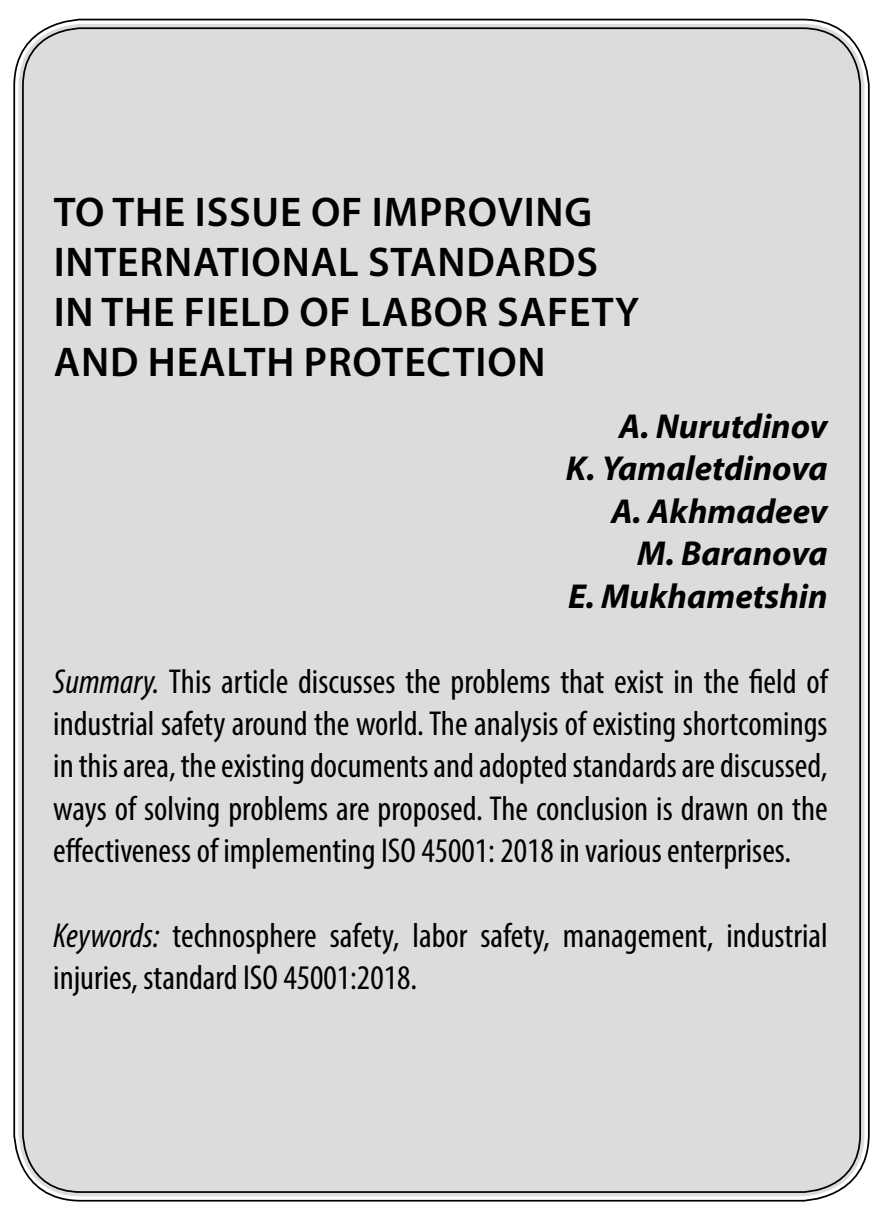

B 2017 году по данным Международной организации по охране труда общее количество несчастных случаев на производстве по всему миру насчитывается до 374 миллионов. При этом, согласно статистике, в мире произошло 2,78 миллиона несчастных случаев со смертельным исходом [12]. Каждый год происходит достаточно множество травм, которые не связаны со смертельным исходом, многие из них приводят к росту количества случаев потери трудоспособности и профессиональной инвалидности. Общее состояние безопасности труда и охраны здоровья в современном мире затруднительно назвать благоприятным.

К основным причинам большинства несчастных случаев на производстве можно отнести недостаточную организацию труда и человеческий фактор, что объясняется несоблюдением инструкций безопасности, неис-

\author{
Нурутдинов Азамат Анварович \\ К.т.н., дочент, Башкирский Государственный \\ Университет, г. Уфа \\ dodger86@yandex.ru \\ Ямалетдинова Клара Шаиховна \\ Д.т.н., профессор, Челябинский Государственный \\ Университет, г. Челябинск \\ clara-yk@yandex.ru \\ Ахмадеев Азат Валерьевич \\ Д.м.н., професссор, Башкирский Государственный \\ Университет, г. Уфа \\ kafedra.bzhd@mail.ru \\ Баранова Мария Сергеевна \\ Башкирский Государственный Университет, г. Уфа \\ mariya.baranova.2014@bk.ru \\ мухаметиин Эмиль Азатович \\ Башкирский Государственный Университет, г. Уфа \\ Mukhametshin.e.a@gmail.com
}

Аннотация. В данной статье рассмотрены проблемы, существующие в 0бласти безопасности на производстве по всему миру. Проведен анализ имеющихся недоработок в данной сфере, обсуждены имеющиеся документы и принятые стандарты, предложены способы решения проблем. Сделан вывод 0 эффективности внедрения ISO 45001:2018 на различных предприятиях.

Ключевые слова: техносферная безопасность, безопасность труда, управление, производственный травматизм, стандарт ISO 45001:2018.

пользованием средств защиты, недостаточной информированностью работников о таких средствах и т.д.

В соответствии с требованиями в ГОСТ Р ИСО 9001:2015 предприятие создает инфраструктуру, обеспечивающую безопасность труда и охрану здоровья работников $[3,11]$. В соответствии с ГОСТ Р ИСО 31000:2010 рекомендуется учитывать конкретные потребности для создания, внедрения и функционирования планов инфраструктуры риск-менеджмента, ее изменяющиеся цели, задачи, структуры, операции, процессы управления, предоставляемые услуги и производимые продукты [7]. В соответствии с требованиями в ГОСТ Р ИСО 14001:2016 устойчивое развитие предприятия достигается балансом между экологическими, социальными и экономическими интересами общества $[2,8]$. Во всех международных стандартах ИСО просле- 
Таблица 1. Цели международных стандартов ISO 9001:2015, ISO 14001:2016, ISO 45001:2018

и OHSAS18001:2007

\begin{tabular}{|c|c|c|}
\hline Стандарт & Наименование системы менеджмента & Цель системы \\
\hline ISO 45001:2018 & $\begin{array}{l}\text { Системы менеджмента безопасности } \\
\text { труда и охраны здоровья. Требования } \\
\text { и руководство по применению }\end{array}$ & $\begin{array}{l}\text { Обеспечить основу для управления рисками и возможностями, } \\
\text { предотвращать связанные с работой травмы и плохое здоровье } \\
\text { работников и обеспечивать безопасные и здоровые рабочие } \\
\text { места. }\end{array}$ \\
\hline ГОСТ Р ИСО 9001:2015 & $\begin{array}{l}\text { Системы менеджмента качества. } \\
\text { Требования }\end{array}$ & $\begin{array}{l}\text { Повышение удовлетворенности потребителей посредством } \\
\text { результативного применения системы менеджмента качества, } \\
\text { включая процессы ее улучшения, и обеспечение соответствия } \\
\text { требованиям потребителей и применимым законодательным } \\
\text { и нормативным правовым требованиям. }\end{array}$ \\
\hline ГОСТ Р ИСО 14001:2016 & $\begin{array}{l}\text { Системы экологического менеджмента. } \\
\text { Требования и руководство } \\
\text { по применению }\end{array}$ & $\begin{array}{l}\text { Предложить организациям подход для защиты окружающей } \\
\text { среды и реагирования на изменяющиеся экологические } \\
\text { условия в балансе с социально-экономическими } \\
\text { потребностями. }\end{array}$ \\
\hline $\begin{array}{l}\text { ГОСТP 54934-2012/ } \\
\text { OHSAS18001:2007 }\end{array}$ & $\begin{array}{l}\text { Системы менеджмента безопасности } \\
\text { труда и охраны здоровья. Требования }\end{array}$ & $\begin{array}{l}\text { Поддержка и распространение передового опыта в области } \\
\text { БТиОЗ при сохранении баланса потребностей в безопасности } \\
\text { труда и социально-экономических потребностей. }\end{array}$ \\
\hline
\end{tabular}

живаются требования к обеспечению и функционированию в рабочем состоянии полной инфраструктуры, необходимой для предоставления услуг и производства продуктов в соответствии с требованиями потребителей. К инфраструктуре относятся здания, рабочее пространство, средства производства; оборудование для управления процессами (технические и программные средства); службы обеспечения транспортом, связью, информационных систем, производственную безопасность среды [9].

В мире накоплен значительный опыт по уменьшению производственного травматизма, широко применяется международный стандарт OHSAS18001:2007 [4]. В международном стандарте OHSAS18001:2007 установлены требования к системам менеджмента в области охраны труда и профессиональной безопасности, направленные к совершенствованию условий труда и поддержанию их функционирования на соответствующем уровне. По данным последних открытых публикаций, количество сертифицированных организаций на соответствие требованиям OHSAS18001 насчитывает около 100000 по всему миру [10]. В 2016 г. OHSAS18001:2007 планировалось заменить подкорректированным, более адаптированным к сегодняшней реальности международным стандартом ISO 45001:2016, внедрение которого способствовало бы снижению количества несчастных случаев на производстве и создание безопасных условий труда, что произошло в марте 2018 г. [1]. Он необходим для предотвращения производственного травматизма, существенного улучшения и обеспечения безопасных условий труда на рабочем месте путём устранения опасностей и сведения к минимуму возможных рисков за счет принятия эффективных профилактических и защитных мер. Основная задача нового международного стандарта ISO 45001:2018 состоит в уменьшении потерь на производстве.

ISO 45001:2018 «Системы менеджмента безопасности труда и охраны здоровья. Требования и руководство по применению» рекомендует различным организациям и промышленным предприятиям методы и средства по уменьшению опасностей, управлению возможными рисками и улучшению условий труда в целом на производстве.

Поскольку стандарт имеет несложную структуру, он подходит для широкого спектра предприятий, независимо то того, к какой отрасли они относятся, что именно производят и какие услуги оказывают. ISO 45001:2018 призван помочь предприятиям в создании безопасных и качественных условий труда при постоянном совершенствовании ими своей деятельности в области безопасности труда и охраны здоровья. В разработке этого документа, важность которого сложно переоценить, участвовали более 70 стран.

Стоит отметить, что одним из существенных достоинств нового стандарта ISO 45001:2018 является его возможность интеграции с другими стандартами систем менеджмента ISO, такими как ISO 9001:2015 и ISO 14001:2016. Использование систем, которые способны дополнять друг друга, делают работу предприятия более результативной, без дополнительных затрат ресурсов для их применения на практике. В таблице 1 приводится сравнение международных стандартов ISO 9001:2015 [5], ISO 14001:2016 [6] и ISO 45001:2018.

Стандарт ISO 45001:2018 основан на применении модели совершенствования деятельности Plan-Do-CheckAct (PDCA), что может минимизировать риски производ- 


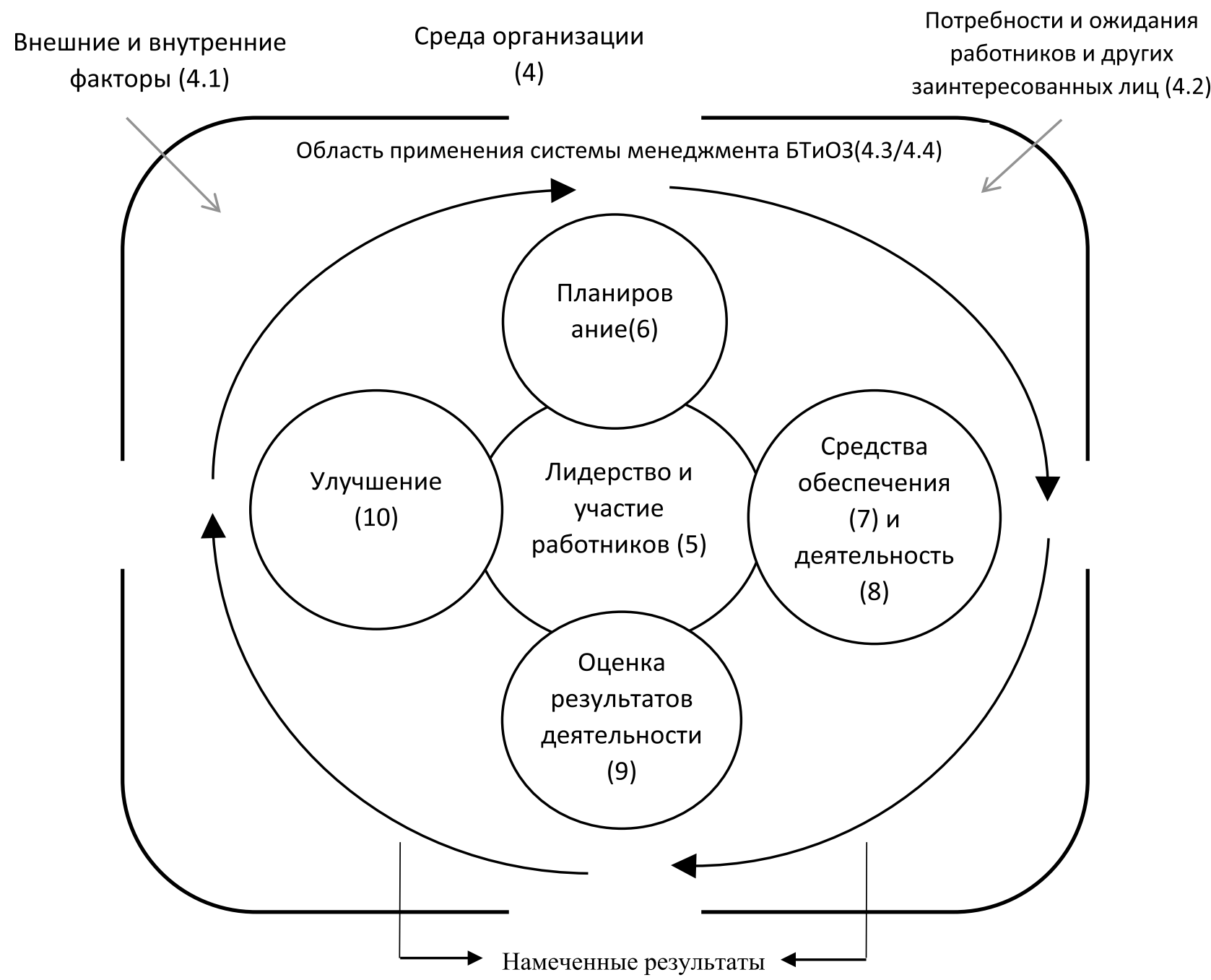

Рис. 1. Связь между PDCA и структурой в ISO 45001:2018

ственного травматизма и позволяет учитывать причины, которые могут привести к долгосрочной потере трудоспособности и несчастным случаям. PDCA - это беспрерывный процесс, который используется организациями для достижения постоянного улучшения. Он может применяться к системе управления в целом и к каждому из ее элементов в отдельности с помощью следующих шагов:

- планируй (включает в себя определение рисков, возможностей СМБТиОЗ, целей, процессов, требуемых для достижения результатов);

- делай (реализация процессов в соответствии с планом);

- проверяй (контроль и измерение достигнутых результатов);

- действуй (включает в себя действия для непрерывного повышения эффективности и для достижения поставленных целей).
Применение концепции PDCA в структуре ISO 45001:2018 показано на рисунке 1. Цифры, указанные в скобках, на рисунках относятся к номерам разделов в стандарте ISO 45001:2018.

Внедрение СМБТиОЗ является стратегическим и оперативным решением для организации. Успех внедрения СМБТиОЗ зависит от лидерства, приверженности руководителя организации к функционированию ISO 45001:2018 во всех уровнях.

В то же время, внедрение и поддержание функционирования СМБТиОЗ на предприятии, ее эффективность и результативность зависят от ряда ключевых факторов, таких как:

- руководство, приверженность, ответственность и подотчетность высшего руководства перед заинтересованными сторонами; 
- культура в организации, которая направлена на результативность ISO 45001:2018 СМБТиО3;

- информированность;

- консультации и участие работников и представителей трудящихся, где они существуют;

- выделение необходимых ресурсов для его поддержания;

- политики СМБТиОЗ, которые совместимы с общими стратегическими целями и направлением деятельности организации;

- эффективный процесс для выявления опасностей, контроля рисков и использования возможностей СМБТиОЗ;

- постоянная оценка эффективности и мониторинг СМБТиОЗ для повышения эффективности;

- интеграция СМБТиОЗ в бизнес-процессы организации;

- цели, которые согласуются с политикой предприятия и учитывают опасности организации, риски и возможности СМБТиО3;

- соблюдение его правовых требований и других требований.

Демонстрация успешной реализации этого документа может быть использована организацией для обеспечения уверенности внутренних и внешних заинтересованных сторон в эффективной СМБТиОЗ. Однако принятие этого документа само по себе не гарантирует предотвращение связанных с работой травм и плохого состояния здоровья для работников, обеспечения безопасных рабочих мест и повышения эффективности предприятия.
Одним из важных пунктов стандарта ISO 45001:2018 СМБТиО3 являются средства и ресурсы для обеспечения функционирования. Этот пункт включает в себя ресурсы (человеческие, природные, инфраструктурные, технологические и финансовые), компетентность (знания и навыки), осведомленность, обмен информацией, документированная информация.

Деятельность СМБТиОЗ организации в то же время предусматривает планирование, осуществление, контроль и поддержку процессов путем:

а) установления критериев для осуществления процессов;

б) осуществления контроля процессов в соответствии с критериями;

в) поддержания и сохранения документированной информации в той мере, в какой это необходимо для уверенности в том, что процессы были выполнены в соответствии с запланированными;

г) адаптации работы к работникам.

В заключение можно отметить, что несмотря на существенные отличия ISO 45001:2018 от OHSAS18001:2007, для соответствия требованиям нового стандарта организациям, ранее внедрившим OHSAS18001:2007, не потребуется менять названия своих документов на термины стандарта ISO. Более того, ISO 45001:2018 имеет хорошую совместимость с ISO 9001:2015 и ISO 14001:2016 и, с учетом объявления ИСО трехлетнего переходного периода, внедрение СМБТиОЗ позволит оптимизировать процессы, направленные на создание безопасных условий труда, и поддерживать их функционирование на высоком уровне.

\section{ЛИТЕРАТУРА}

1. ISO 45001:2018. Occupational health and safety management systems - Requirements with guidance for use.

2. Бондарук, А. М. Система экологического менеджмента на предприятии / А. М. Бондарук, Р. Н. Гимаев, С.И.Пыхов, К. Ш. Ямалетдинова // Экология и промышленность России. 2008. № 4. С. 29-31.

3. Габидуллин, И. Ф. Внедрение систем менеджмента качества в многоуровневом образовательном процессе вуза / И. Ф. Габидуллин, К. Ш. Ямалетдинова, Г. Ф. Ямалетдинова, 3. А. Янгуразова // Вестник Оренбургского государственного университета. 2014. № 3 (164). С. $78-83$.

4. ГОСТ P 54934-2012/0HSAS18001:2007. Системы менеджмента безопасности труда и охраны здоровья. Требования.— М.: Стандартинформ, 2012.— 26 с.

5. ГОСТ Р ИС0 9001-2015. Системы менеджмента качества Требования.- М.: Стандартинформ, 2015.— 32 с.

6. ГоСТ Р ИС0 14001-2016 Системы экологического менеджмента. Требования и руководство по применению. — М.: Стандартинформ, 2016. - 39 с.

7. Гоц, С.С. К вопросу о количественной оценке характеристик техногенных рисков на предприятиях нефтегазового комплекса / С. С. Гоц, К. Ш. Ямалетдинова, А. М. Бондарук, М. Р. Гимаев, Д. С. Пыхов // Проблемы сбора, подготовки и транспорта нефти и нефтепродуктов. 2011. № 2 (84). С. $109-115$.

8. Дудников, Ю. В. Анализ системы экологического менеджмента со стороны высшего руководства в соответствии с новой редакцией ГОСТ Р ИСО 140012016 / Ю. В. Дудников, Э. А. Гареев, К. Ш. Ямалетдинова, С. И. Пыхов, А. А. Нурутдинов, Т. М. Зайнашев // Наукоемкие технологии в решении проблем нефтегазового комплекса в год экологии в России. Материалы VII Международной научной конференции. отв. редактор К. Ш. Ямалетдинова. — Уфа: РИЦ БашГУ, 2017.-С. 187-189.

9. Пыхов, С. И. Совершенствование деятельности предприятия на базе всеобщего управления качеством / С. И. Пыхов, А. А. Ямалетдинова, А. А. Нурутдинов, А. А. Шарипова, В. А. Гоц // Инновации и наукоемкие технологии в образовании и экономике. Материалы VI Международной научно-практической конференции. Ответственный редактор К. Ш. Ямалетдинова. 2017. С. 36-37.

10. Результатом встречи разработчиков ISO 45001 может стать перенос сроков публикации стандарта [Электронный pecypc] — URL: https://1cert.ru/novosti/ rezultatom-vstrechi-razrabotchikov-iso-45001-mozhet-stat-perenos-srokov-publikatsii-standarta (дата обращения: 10.06.2020) 
11. Хисамиева, Г. М. Совершенствование системы профессионального образования — один из способов улучшения качества персонала на предприятиях нефтехимической промышленности / Г. М. Хисамиева, А. М. Бондарук, К. Ш. Ямалетдинова., С. И. Пыхов // Проблемы сбора, подготовки и транспорта нефти и нефтепродуктов. 2009. № 2 (76). С. 137-140.

12. Ямалетдинова, К. Ш. Тренд развития международных стандартов ИСО в Год экологии в России / К. Ш. Ямалетдинова, А. А. Нурутдинов, А. А. Ямалетдинова // Инновации и наукоемкие технологии в образовании и экономике. Материалы VI Международной научно-практической конференции. Ответственный редактор К. Ш. Ямалетдинова. — Уфа: РИЦ БашГУ, 2017.— С. 96-98.

( ) Нурутдинов Азамат Анварович ( dodger86@yandex.ru ), Ямалетдинова Клара Шаиховна ( clara-yk@yandex.ru ),

Ахмадеев Азат Валерьевич ( kafedra.bzhd@mail.ru ), Баранова Мария Сергеевна ( mariya.baranova.2014@bk.ru ),

Мухаметшин Эмиль Азатович ( Mukhametshin.e.a@gmail.com ).

Журнал «Современная наука: актуальные проблемы теории и практики»

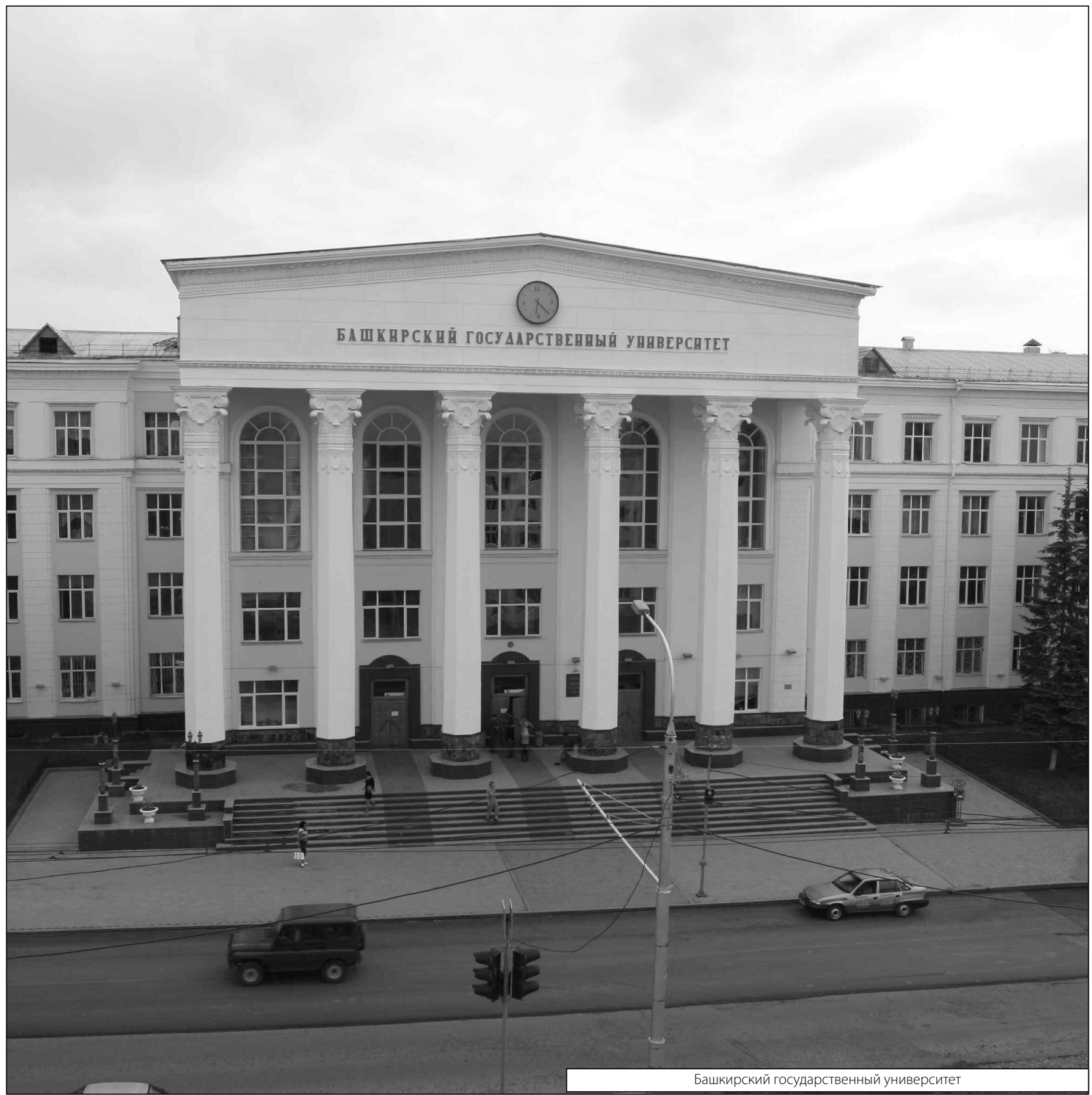

